\title{
Enzymes go big: surface hydrolysis and functionalisation of synthetic polymers
}

\author{
Georg M. Guebitz ${ }^{1}$ and Artur Cavaco-Paulo ${ }^{2}$ \\ ${ }^{1}$ Department of Environmental Biotechnology, Graz University of Technology, Petersgasse 12, 8010 Graz, Austria \\ ${ }^{2}$ Department of Textile Engineering, University of Minho, 4800 Guimaraes, Portugal
}

\begin{abstract}
Enzyme technology has progressed from the biotransformation of small substrates to biotransformation of synthetic polymers. Important breakthroughs have been the isolation and design of novel enzymes with enhanced activity on synthetic polymer substrates. These were made possible by efficient screening procedures and genetic engineering approaches based on an in-depth understanding of the mechanisms of enzymes on synthetic polymers. Enhancement of the hydrophilicity of synthetic polymers is a key requirement for many applications, ranging from electronics to functional textile production. This review focuses on enzymes that hydrolyse polyalkyleneterephthalates, polyamides or polyacrylonitriles, specifically on the polymer surface thereby replacing harsh chemical processes currently used for hydrophilisation.
\end{abstract}

\section{Introduction}

Biocatalytic processes are well established for synthetic biotransformation of small molecules. In 2004, economists predicted a 25 -fold increase in turnover for polymers processed by biotechnological methods up till 2010, compared with only a seven-fold turnover increase for fine chemicals $[1,2]$. Recent launches of new commercial products, such as enzymes for processing polyester (Inotex Ltd; http://www. inotex.cz/) and patents by major industrial players (Genencor, http://www.genencor.com/; Novozymes, http:// www.novozymes.com/en; CIBA, http://www.cibasc.com/; Henkel, http://www.henkel.com/; [3-6]) indicate that enzymes are going 'big' in terms of their substrates.

Limited surface hydrolysis of polyalkyleneterephthalates (PAT), polyamides (PA) and polyacrylonitriles (PAN) by enzymes increases their hydrophilicity, which is a key requirement for many applications, including gluing, painting, inking, anti-fogging, filtration, textile production, electronics and applications in the biomedical field (Box 1) [2,7-10].

Synthetic polymers are coated with bioactive compounds for many applications, including applications in textile manufacturing, microelectronics, bioprocessing and medical and food packaging. For example, biocoating of PET can lead to biocompatible and/or haemocompatible materials and antimicrobial surfaces, and is also used in tissue engineering [11]. Surface hydrophilisation is an important step in the biocoating process. PET is also used

Corresponding author: Guebitz, G.M. (guebitz@tugraz.at). in cardiovascular implants such as artificial heart valve sewing-rings and artificial blood vessels. Enhanced hydrophilicity of PET (i.e. $15^{\circ}$ lower contact angle) in these applications has led to reduced bacterial adhesion, thereby reducing the risk of infection [12]. PET shows excellent properties for use as a transparent cover layer in Flexible Electronic Devices (FEDs) (e.g. displays or photovoltaic cells), including mechanical stability and resistance to oxygen and water vapour. Again, the PET surface must be rendered more hydrophilic for increased adhesion of the subsequent functional layers, which have a major affect on the FED performance, efficiency and lifetime [9].

Ultrafiltration is used in many processes, including water purification and/or desalination, wastewater treatment and separations in the food, dairy, paper, textile, chemical and biochemical industries. Membrane fouling by proteins and other biomolecules increases the energy demand for filtration and requires cleaning with aggressive chemicals or replacement of the membrane. Ultrafiltration and reversed osmosis devices based on polyamide or polyacrylonitrile can be rendered more hydrophilic by grafting poly(ethylene glycol) (PEG) to the devices, or by polymerisation of acrylate monomers to the devices, which increases resistance to fouling [10,12-15].

Textile materials made of PA and PET are uncomfortable to wear because perspiration cannot penetrate the materials and evaporate. This poor water permeability is due to the hydrophobicity of synthetic polymers, which also leads to static cling and stain retention during laundering. A variety of different plasma treatments had been investigated to increase hydrophilicity for PET, PA and PAN fabrics and films [16-20]. Chemical finishers, for example those based on hydrophilic carboxyl-containing polymers, are widely used to increase hydrophilicity of synthetic textiles and are continuously being improved, as evidenced by numerous patents filed [21]. In addition to these benefits to potential users of the relevant products, increased hydrophilicity also makes polymer processing (e.g. dying) more efficient [7]. Alkaline treatment of polyester can improve texture and hydrophilicity, and reduce pilling. However, extremely high weight losses from 10 $30 \%$ have been reported for this treatment [22]. Similarly, alkaline hydrogen peroxide or concentrated strong acid treatments for hydrolysing nitrile groups of PAN are difficult to control and have a negative impact on the environment [16]. By contrast, enzyme hydrolysis is targeted to the surface of the polymers while the bulk properties of the polymers remain un-changed. 


\section{Box 1. Synthetic fibres}

About $90 \%$ of all synthetic fibres are made from either polyethylene terephtalate (PET), polyamides (PA) and polyacrylonitrile (PAN). Synthetic fibres already hold a $54 \%$ market share in the fibre market and $>25$ million tones (Mt) of PET, 5Mt PA and 2.6Mt PAN are produced annually [32]. PET alone is forecasted to account for almost $50 \%$ of all fibre materials in 2008 (see Journal for Asia on Textile and Apparel (ATA), http://www.adsale.com.hk/pub/en/ata_ index.asp, issue 2006/06).

There is no doubt that synthetic polymers have unique properties, such as high uniformity, mechanical strength or resistance against chemicals or abrasion. However, high hydrophobicity, the build-up of static charges, not allowing 'breathing' and being difficult to finish are undesirable properties of synthetic materials $[2,3,16,49]$. In this article, we show how enzymes can be used to increase the hydrophilicity of synthetic polymers.

\section{How to quantify success?}

Enzymatic modification of PAT, PA and PAN materials involves limited hydrolysis of backbone esters, amide bonds, or of nitrile groups, respectively (Figure 1). The resulting changes of surface properties can easily be quantified with simple methods such as tensiometry or hydrophilicity measurements (e.g. contact angle) [23]. However, it is considerably more difficult to quantify the corresponding chemical changes on the polymer surface, for example the increase of carboxyl groups. If nitrile groups of PAN are converted to the corresponding acids, the concomitant release of ammonia can be used to quantify turnover of the biotransformation [24] (Figure 1). In the case of PA and PAT, hydrolysis would lead to the solubilisation of the resulting smaller fragments at a certain point, and this can be quantified by HPLC (high performance liquid chromatography) [2] and other methods [25]. However, it is not the aim of enzymatic surface treatment to liberate these soluble oligomers and thus 'degrade' the polymer. Instead, limited hydrolysis in the middle of the polymer chain is desired because it leads to the production of novel functional groups. Derivitisation of these functional groups (e.g. amino groups) is another possibility for quantifying surface hydrolysis based on colour changes using agents such as 2,4,6-trinitrobenzenesulfonic acid or $\alpha$-bromoacrylamido reactive dyes [26].

X-ray photoelectron spectroscopy (XPS) has been proven to be a powerful tool for quantifying surface chemical changes created by enzymatic modification of PAN, PET and polypropylene $[2,4,16,24,27,28]$. In addition to XPS, attenuated total reflectance-Fourier transform infrared spectroscopy (ATR-FTIR) and scanning electron microscopy (SEM) have been used to analyse surface hydrolysis of polyacrylonitriles, and solid-state nuclear magnetic resonance (NMR) has been used to confirm enzymatic conversion of ${ }^{13} \mathrm{C}$-labelled PAN into polyacrylic acid during bacterial growth on this substrate [29]. Angle-resolved

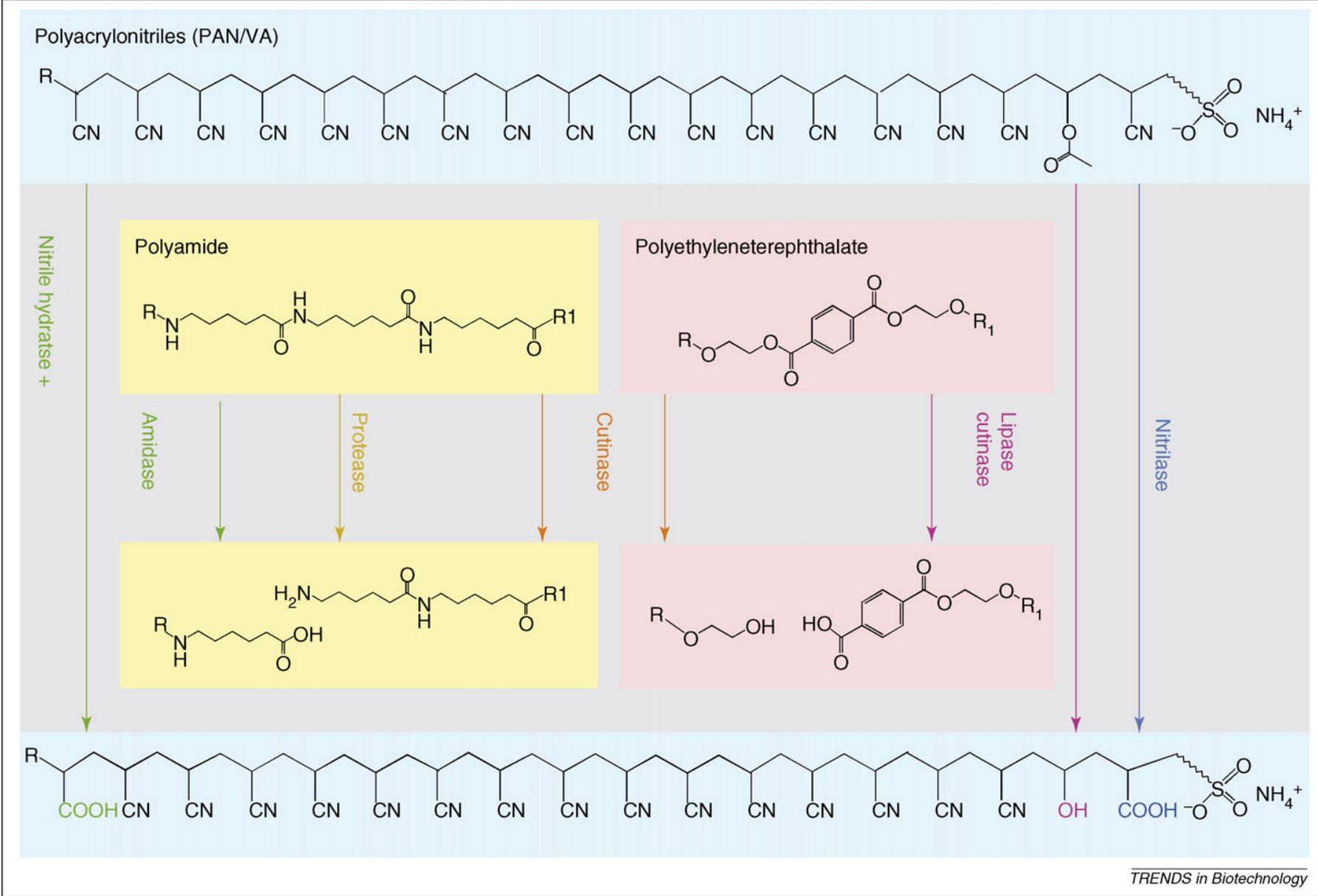

Figure 1. Enzymatic hydrolysis of synthetic polymers (amidase hydrolyses amides formed from PAN by nitrile hydratase; lipases and cutinases hydrolyse vinyl-acetate moieties in PAN). 
XPS has been used to measure the thickness of protein (enzyme) layers on the PET surface, which often led to misinterpretation of results [2]. Thus, it is important to consider the contribution of protein adsorption during enzyme treatment on measured values of surface properties such as hydrophilicity. Most researchers use severe washing procedures with ultrasound or organic solvents and compare their results to controls run with inhibited enzymes [4].

\section{Enzymatic hydrolysis of polyacrylonitrile}

Polyacrylonitrile is a collective name for all polymers that consist of at least $85 \%$ acrylonitrile monomer. The typical PAN textile fibre consists of 89-95\% acrylonitrile, 4-10\% non-ionic co-monomer (e.g. vinyl acetate) and $\sim 1 \%$ ionic comonomer, containing a sulpho $\left(\mathrm{SO}_{3} \mathrm{H}\right)$ or sulphonate $\left(\mathrm{OSO}_{3} \mathrm{H}\right)$ group. Recently it has been shown that bacteria (a novel strain of Micrococcus luteus) can degrade PAN fibres. During this process, polyacrylic acid was released from PAN that was ${ }^{13} \mathrm{C}$-labelled for NMR analysis [29]. The release of polyacrylic acid from PAN, together with the formation of ammonia, was also shown for commercial nitrilases [30].

Several researchers have shown that nitrile groups of PAN can be converted to the corresponding acids or amides by nitrilases or by an enzyme system consisting of nitrile hydratase and amidase, respectively, and major increases in hydrophilicity were found $[16,27,29]$ (Table 1). These changes in surface properties corresponded to increases of the surface oxygen-to-carbon $(\mathrm{O} / \mathrm{C})$ ratio by up to $80 \%$ owing to enzymatic hydrolysis of the nitrile groups, as quantified with XPS [27,28].

Commercial PAN-based materials usually contain $\sim 7 \%$ vinyl acetate to reduce rigidity of the polymer. The vinyl acetate moieties in PAN can be hydrolysed by cutinases and lipases, making this approach applicable to most commercially available PANs [31]. Factors that influence the enzymatic activity are crystallinity and accessibility of nitrile groups. High crystallinity of certain PAN materials has been shown to have a negative influence on susceptibility to enzymatic hydrolysis [29]. Although the accessibility of nitrile groups to enzymes can be increased by the presence of solvents such as dimethylacetamide or dimethylformamide, the use of organic solvent is not desirable owing to environmental and safety concerns [24,30].

\section{Enzymatic hydrolysis of polyamides}

The first important polyamide was Nylon 66, produced by the reaction of adipic acid and hexamethylene diamine. Several structural modifications with differing temperature capabilities have become commercially available, including Nylon 46, 610, 612, 6, 11, and so on. Polyamides have applications in many areas, the most important being in the production of fibre-based materials [32].

Enzymes that can hydrolyse polyamides are proteases, amidases and cutinases (Table 1). A model substrate (adipic acid bishexyl-amide) has been developed for screening polyamidase activity of a given enzyme. For a protease from Beauveria sp., an amidase from Nocardia sp. and a cutinase from Fusarium solani, activity on this model

Table 1. Enzymatic modification of synthetic polymers

\begin{tabular}{|c|c|c|c|}
\hline Enzyme & Organism & Analysis method & Refs \\
\hline \multicolumn{4}{|c|}{ Polyacrylonitrile (PAN) } \\
\hline \multirow[t]{4}{*}{ Nitrile hydratase } & Rhodococcus rhodochrous & XPS, $\mathrm{NH}_{3}$ formation, dye-binding assay & [24] \\
\hline & Arthrobacter sp & XPS & [27] \\
\hline & $\begin{array}{l}\text { Brevibacterium imperiale; } \\
\text { Corynebacterium nitrilophilus }\end{array}$ & XPS, dye-binding assay, contact angle & {$[16]$} \\
\hline & Micrococcus luteus & $\mathrm{NMR}, \mathrm{NH}_{3}$ formation, dye-binding assay & [29] \\
\hline \multirow[t]{2}{*}{ Nitrilase } & Agrobacterium tumefaciens & XPS, FTIR, SEM, dye-binding assay & [28] \\
\hline & Commercial enzyme & $\mathrm{NH}_{3}$ and polyacrylic acid formation, dye-binding assay & [30] \\
\hline Cutinase $^{a}$ & Fusarium solani & X-ray diffraction, formation of acetic acid, dye-binding assay & [31] \\
\hline Lipase $^{a}$ & Thermomyces lanuginosus & & \\
\hline \multicolumn{4}{|c|}{ Polyethyleneterephthalate (PET) } \\
\hline \multirow[t]{5}{*}{ Cutinase } & Thermobifida fusca & Release of terephthalic acid, hydrophilicity & {$[48,57]$} \\
\hline & Penicillium citrinum & Release of oligomers, hydrophilicity & [52] \\
\hline & Fusarium oxysporum & Release of terephthalic acid, hydrophilicity & {$[50,57]$} \\
\hline & Fusarium solani & & \\
\hline & Fusarium solani & XPS, Release of oligomers & [2] \\
\hline \multirow[t]{3}{*}{ Lipase } & Candida antarctica & & \\
\hline & $\begin{array}{l}\text { Humicola sp., Candida sp., } \\
\text { Pseudomonas sp. }\end{array}$ & Depilling assay, Release of hydrolysis products, hydrophilicity & [5] \\
\hline & Thermomyces lanuginosus & Release of oligomers, hydrophilicity & [23] \\
\hline Serine esterase & Pseudomonas spp. & $\begin{array}{l}\text { Release of terephthalic acid, dye-binding assay, hydrophilicity, depilling } \\
\text { assay }\end{array}$ & {$[3,49]$} \\
\hline $\begin{array}{l}\text { Nitro-benzyl- } \\
\text { esterases }\end{array}$ & Bacillus sp. & $\begin{array}{l}\text { Hydrolysis of bis-( } p \text {-methylbenzoic acid)-ethylenglycol ester, } \\
\text { dimethylterephtalate and diethylterephthalate, depilling }\end{array}$ & [6] \\
\hline \multicolumn{4}{|l|}{ Polyamide (PA) } \\
\hline \multirow[t]{2}{*}{ Protease } & Bacillus subtilis & Release of oligomers, reactive dye-binding assay, hydrophilicity & [33] \\
\hline & Beauveria sp. & Release of oligomers, hydrophilicity & [23] \\
\hline Cutinase & Fusarium solani pisi & $\begin{array}{l}\text { Release of oligomers, reactive dye-binding assay, hydrophilicity } \\
\text { hydrophilicity }\end{array}$ & $\begin{array}{l}{[33]} \\
{[23]}\end{array}$ \\
\hline Amidase & Nocardia sp. & Release of oligomers, hydrophilicity & [23] \\
\hline Hydrolase & Arthrobacter sp. & Release of hydrolysis products from 6-aminohexanoate-dimer & [37] \\
\hline
\end{tabular}

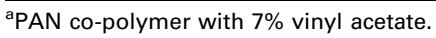


substrate correlated with hydrolysis activity in polyamide [23]. This cutinase has been genetically modified with the aim of achieving higher activity on synthetic polymers and the resulting L182A cutinase mutant showed increased PA-hydrolysing activity when compared with the native enzyme [33,34]. Similarly, the activity of a nylon-oligomer hydrolysing enzyme EII' from Flavobactererium sp. was increased 200-fold by genetic engineering [35]. In addition to genetic engineering, reaction engineering (i.e. influencing reaction mix, temperature and additives) seems to be an important factor and enzymatic hydrolysis of PA can be increased in the presence of solvents [36].

Linear and cyclic nylon oligomers are undesirable byproducts in Nylon production that are released into the environment. Negoro and co-workers described the enzymatic degradation of these by-products by bacteria [37] Several bacteria, including Arthrobacter sp., grow on the 6aminohexanoate-cyclic dimer as the sole carbon and nitrogen source. Under these conditions 6-aminohexanoate hydrolases are produced. Similar to the penicillin-recognizing family of serine-reactive hydrolases, an oxyanion of the substrate is formed as a common intermediate, which is stabilised by the positively charged nitrogen at Ser112 and Ile345 in the case of the 6-aminohexanoate-dimer hydrolase [37].

In addition to hydrolytic enzymes, oxidases from lignolytic fungi have been shown to depolymerise polyamides [38-40]. Nylon-degrading peroxidases attack methylene groups adjacent to the nitrogen atoms and the reaction then proceeds in an auto-oxidative manner [40,41]. Nylon degradation capability of Bjerkandera adusta was ascribed to the activity of two manganese-peroxidases [39]. In general, degradation of polyamide with oxidative enzymes seems to be difficult to control and therefore has less potential for commercial applications of surface functionalisation.

\section{Enzymatic hydrolysis of polyesters}

Enzymes have shown potential both for synthesis of functional polyesters and for surface functionalisation and grafting. Lipases have been used for the synthesis of bifunctional polyesters [42], biocompatible sorbitol-containing polyesters [43] and for polyester coating of cellulose [44]. The enzymatic synthesis of chiral polyesters with high optical purity, which have applications as responsive materials in stereoselective reactions, is difficult to achieve using other approaches [45]. Attachment of novel sidechains (grafting) on poly(styrene-co-4-vinylbenzyl alcohol) was achieved by lipase-catalysed ring-opening polymerisation [46]. Recently, stereoselective grafting from polymers containing defined ratios of enantiomeric secondary alcohols was achieved [47].

PET is a polymer of ethylene glycol and terephthalic acid, produced from purified terephthalic acid (PTA) or alternatively, dimethyl terephthalate (DMT), and ethylene glycol. In addition to fibre production, a minor share of PET produced is used for packaging (30\%) and other applications (5\%). Enzymes are potential tools for PET recycling [48], for targeted surface hydrolysis of PAT-based materials and for depilling of PAT fabrics during washing processes [49].
PAT hydrolysing enzymes have been reported among cutinases, lipases and esterases (Table 1). PET was hydrolysed by cutinases from $F$. solani and $F$. oxysporum $[2,34,50,51]$ and from Pencillium citrinum [52]. Based on the same activity on $p$-nitrophenyl butyrate, the $F$. oxysporum cutinase released more terephthalic acid from PET and increased the hydrophilicity to a greater extent than the $F$. solani enzyme [50]. Other PAT-hydrolysing enzymes, such as those from Humicola sp., Candida sp., Pseudomonas sp. and Thermomyces lanuginosus, are typical lipases $[3,5,23,49]$.

Cutinases that hydrolyse PATs can also hydrolyse polyamides and vinyl acetate moieties of PAN (Figure 1). Hydrolysis activity of nylon oligomers by a 6-aminohexanoate-dimer hydrolase emerged in an enzyme with esterase activity [37]. Such catalytic promiscuity has been previously reported and exploited [53,54]. Structural elements (loops) of various hydrolases, including cutinase from $F$. solani and acetyl xylanesterase from $P$. citrinum, were engineered into the structure of the smallest known lipase (lipase A from Bacillus subtilis). These fragments still showed considerable activity, indicating that this might be a promising approach for developing novel enzymes for particular applications, including polymer surface hydrolysis $[55,56]$.

A major parameter that can be improved by surface hydrolysis of aromatic polyesters is hydrophilicity [50,5759]. However, in addition to enzymatic hydrolysis, the simple adsorption of enzyme protein to the polymer can also increase the hydrophilicity of PET owing to the hydrophilicity of the protein. Using XPS analysis an increase in nitrogen content of up to $7.2 \%$ owing to adsorption of a lipase to PET was measured, and angle-resolved XPS confirmed the presence of protein layers with thicknesses of 1.6-2.6 $\mathrm{nm}$ and 2.5-2.8 $\mathrm{nm}$ in PET treated with cutinase from $F$. solani and lipase from $C$. antarctica, respectively [2].

High crystallinity negatively affects the ability of the enzymes to hydrolyse PET, which has been shown for enzymes from $F$. solani and from $T$. fusca, as well as for an experimental polyesterase from Danisco (http:// www.danisco.com/cms/connect/) $[2,49,60]$.

\section{Improving polymer-hydrolysing enzymes}

Polymer-hydrolysing enzymes should be highly active on water-insoluble polymers. Only a few known and/or commercially used esterases and lipases were able to hydrolyse PET when dosed with the same activity on $p$-nitrophenyl butyrate $[23,50]$. To make screening procedures more efficient, easy-to-analyse oligomeric PET and PA model substrates have been developed and novel polyesterases and polyamidases identified [52]. In terms of surface functionalisation, these enzymes should be endo-acting. This means that bonds should preferentially be hydrolysed centrally in the polymer and not only on the chain ends. This would avoid the release of short-chain oligomers and furthermore provide evenly distributed increasing hydrophilicity [23]. The mode of action of enzymes on PET substrates can be modified with changes to reaction conditions. It has been reported that the ratio of the ethyleneglycolmono-ester of terephthalic acid to terephthalic 

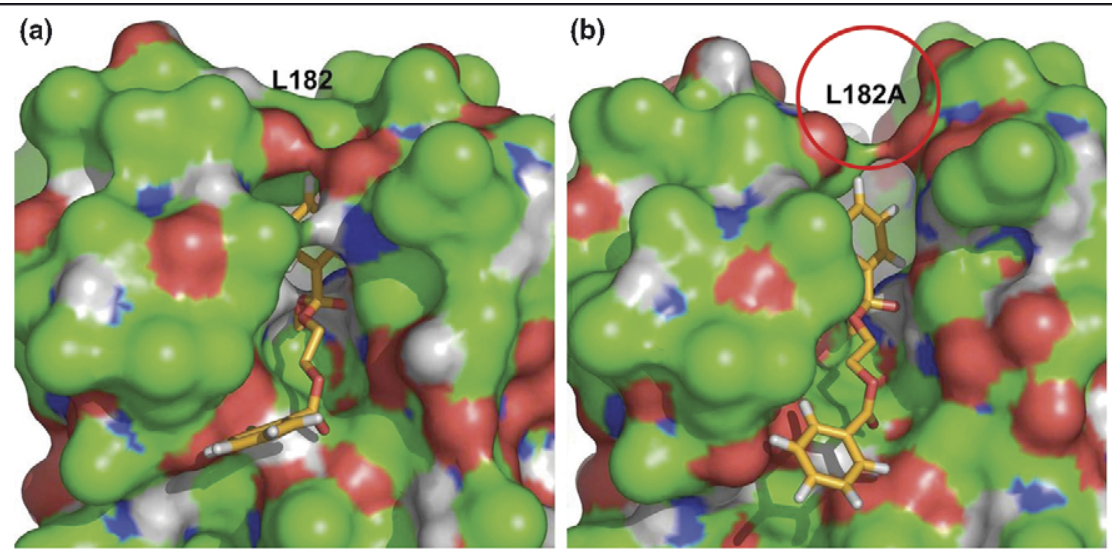

$\overline{\text { TRENDS in Biotechnology }}$

Figure 2. Single exchanges of amino acids of a cutinase from $F$. solani (a) leads to enlargement of the active site and better accommodation of a PET model substrate shown by the red circle in (b). L182A mutation is responsible for better stabilization of the 1,2-ethanodiol dibenzoate tetrahedral intermediate and for five-fold higher activity on PET [34].

acid detected in solution depends on the enzyme-(i.e. $F$. solani cutinase)-to-substrate ratio $[2,61]$.

Only recently, the potential of genetic engineering to make polyesterases more 'fit' for their polymeric substrates was demonstrated (Figure 2). Site-directed mutagenesis of a cutinase from $F$. solani was carried out to enlarge the active site, which could then better accommodate polymeric substrates [34]. Single amino acid replacements were shown to better stabilise the PET model substrate 1,2-ethanodiol dibenzoate tetrahedral intermediate at the enzyme active site (Figure 2). Several cutinase mutants, all of which exhibited an enlarged active site, showed up to five-fold higher activity on PET. The structure and function of cutinases are well studied, and genetic engineering was previously used to improve their properties for several applications: for example, fat stain removal in detergents [62-65].

As well as the architecture of the active site other structural elements of the enzymes, such as the regions necessary for sorption and for guiding the enzyme along the substrate, might be important for polymer hydrolysis. It is well established that cellulose-binding modules (CBM) fulfill these functions in cellulases. More recently, a CBM has been attached to the $C$. antarctica lipase $\mathrm{B}$, which is used for polyester coating of cellulose [44]. Similarly, enzymes hydrolysing microbial polyesters (i.e. polyalkanoate depolymerases) have binding domains with an essential function for PHA (polyhydroxyalkanoate) hydrolysis [66]. In nature, fungi have also developed strategies to direct enzymes to the surface of hydrophobic polymers. Aspergillus oryzae uses the hydrophobin RolA protein, and also the even more hydrophilic protein HsbA, to recruit high levels of its cutinase (CutL1) onto the surface of the polyester polybutylene succinate-coadipate (PBSA). RolA was also shown to move laterally on the PBSA film surface $[67,68]$. The potential influence of structural elements responsible for binding in polyesterases and the possible role of hydrophin-like molecules in the enzymatic PET hydrolysis remain to be investigated.

\section{Conclusion and perspectives}

Enhancement of the hydrophilicity of synthetic polymers is a key requirement for many applications ranging from electronics to functional textile manufacture. Enzymes have proved to be environmentally friendly tools for hydrolysis of synthetic polymers, specifically on the polymer surface, without compromises in polymer bulk properties such as strength. Screenings with short-chain model substrates has led to identification of novel polymer-modifying hydrolases suitable for industrial applications such as PET processing [3,5,6]. However, the power of genetic engineering approaches has not yet been fully exploited. A better understanding of the interaction of the enzyme with the substrate with regard to factors such as sorption, movement on the polymer surface, and the role of hydrophobins or binding modules, will be necessary to develop enzymes with further enhanced activity.

\section{Acknowledgements}

The authors wish to thank the European Commission [RTD (Research, Techology, Development)-Biosyntex], the Research Centre of Applied Biocatalysis and CIBA Sc for support of this work.

\section{References}

1 Festel, G. et al. (2004) Der einfluss der biotechnologie auf produktionsverfahren in der chemieindustrie. Chem.-Ing.-Tech. 76, 307-312

2 Vertommen, M.A.M.E. et al. (2005) Enzymatic surface modification of poly(ethylene terephthalate). J. Biotechnol. 120, 376386

3 Kellis, J. et al. Genencor. Enzymatic modification of the surface of a polyester fiber or article, US 6,254,645 B1

4 Hasmann, A. et al. Ciba. European Patent Application. Enzymatic hydrophilization of polypropylene surfaces, 06117992.5

5 Andersen, B.K. et al. Novozymes. Method of treating polyester fabrics, $5,997,584,1-20$

6 Michels, A. et al. Henkel. Use of esterases for separating plastics, PCT/ EP2006/007693 edn

7 Makhlouf, C. et al. (2007) Graft copolymerization of acrylic acid onto polyamide fibers. Appl. Surf. Sci. 253, 5521-5528

8 Yang, P. et al. (2003) Confined photo-catalytic oxidation: a fast surface hydrophilic modification method for polymeric materials. Polym. 44, $7157-7164$

9 Laskarakis, A. et al. (2007) Surface modification of poly(ethylene terephthalate) polymeric films for flexible electronics applications. Thin Solid Films DOI: 10.1016/j.tsf.2007.03.170 (http://www. sciencedirect.com/science/journal/00406090)

$10 \mathrm{Kim}$, H.A. et al. (2007) Comparison of initial filtration resistance by pretreatment processes in the nanofiltration for drinking water treatment. Separ. Purif. Technol. 56, 354-362 
11 Goddard, J.M. and Hotchkiss, J.H. (2007) Polymer surface modification for the attachment of bioactive compounds. Prog. Polym. Sci. 32, 698-725

$12 \mathrm{Li}$, J.X. et al. (2007) The influence of polyethylene terephthalate surfaces modified by silver ion implantation on bacterial adhesion behavior. Surf. Coatings Technol. 201, 8155-8159

13 Asatekin, A. et al. (2007) Anti-fouling ultrafiltration membranes containing polyacrylonitrile-graft-poly(ethylene oxide) comb copolymer additives. J. Membr. Sci. 298, 136-146

14 Reddy, A.V.R. et al. (2005) Fouling resistant membranes in desalination and water recovery. Desalination 183, 301306

15 Qiao, X. et al. (2007) Hydrophilic modification of ultrafiltration membranes and their application in Salvia Miltiorrhiza decoction. Separ. Purif. Technol. 56, 265-269

16 Battistel, E. et al. (2001) Enzymatic surface modification of acrylonitrile fibers. Appl. Surf. Sci. 177, 32-41

17 De Geyter, N. et al. (2007) Treatment of polymer films with a dielectric barrier discharge in air, helium and argon at medium pressure. Surf. Coatings Technol. 201, 7066-7075

18 Negulescu, I.I. et al. (2000) Characterizing polyester fabrics treated in electrical discharges of radio-frequency plasma. Text. Res. J. 70, $1-7$

19 McCord, M.G. et al. (2002) Modifying nylon and polypropylene fabrics with atmospheric pressure plasmas. Text. Res. J. 72, 491498

20 Pane, S. et al. (2001) Acrylic fabrics treated with plasma for outdoor applications. J. Ind. Textiles 31, 135-145

21 Soane, D.S. et al. (2006) US-Patent. Hydrophilic finish for fibrous substrates. 20060090648

22 Zeronian, S.H. and Collins, M.J. (1989) Surface modification of polyester by alkaline treatments. Text. Progr. 20, 1-34

23 Heumann, S. et al. (2006) New model substrates for enzymes hydrolysing polyethyleneterephthalate and polyamide fibres. $J$. Biochem. Biophys. Methods 69, 89-99

24 Tauber, M.M. et al. (2000) Nitrile hydratase and amidase from Rhodococcus rhodochrous hydrolyse acrylic fibers and granulates. Appl. Environ. Microbiol. 66, 1634-1638

25 O'Neill, A. and Cavaco-Paulo, A. (2004) Monitoring biotransformations in polyesters. Biocat. Biotrans. 22, 353-356

26 Silva, C. and Cavaco-Paulo, A. (2004) Monitoring biotransformations in polyamide fibres. Biocat. Biotrans. 22, 357-360

27 Wang, N. et al. (2004) Enzymatic surface modification of acrylic fiber. AATCC Review 4, 28-30

28 Fischer-Colbrie, G. et al. (2006) Surface modification of polyacrylonitrile with nitrile hydratase and amidase from Agrobacterium tumefaciens. Biocat. Biotrans. 24, 419-425

29 Fischer-Colbrie, G. et al. (2007) Surface hydrolysis of polyacrylonitrile with nitrile hydrolysing enzymes from Micrococcus luteus BST20. $J$. Biotechnol. 129, 62-68

30 Matama, T. et al. (2007) Using a nitrilase for the surface modification of acrylic fibres. Biotechnol. J. 2, 353-360

31 Matama, T. et al. (2006) The effect of additives and mechanical agitation in surface modification of acrylic fibres by cutinase and esterase. Biotechnol. J. 1, 842-849

32 Saurer Management, A.G. (2006) The Fiber Year 2005/06, The Saurer Group

33 Silva, C. et al. (2007) Influence of mechanical agitation on cutinases and protease activity towards polyamide substrates. Enzyme Microb. Technol. 41, 867-875

34 Araujo, R. et al. (2007) Tailoring cutinase activity towards polyethylene terephthalate and polyamide 6, 6 fibers. J. Biotechnol. 128, 849-857

35 Negoro, S. (2000) Biodegradation of nylon oligomers. Appl. Microbiol. Biotechnol. 54, 461-466

36 Silva, C. et al. (2005) Influence of organic solvents on cutinase stability and accessibility to polyamide fibers. J. Polym. Sci. 43, 2749-2753

37 Negoro, S. et al. (2007) Nylon-oligomer degrading enzyme/substrate complex: Catalytic mechanism of 6-aminohexanoate-dimer hydrolase. J. Mol. Biol. 370, 142-156

38 Klun, U. et al. (2003) Polyamide 6 fibre degradation by a lignolytic fungus. Polym. Degrad. Stab. 79, 99-104
39 Friedrich, J. et al. (2007) Ability of fungi to degrade synthetic polymer nylon-6. Chemosphere 67, 2089-2095

40 Deguchi, T. et al. (1998) purification and characterization of a nylon-degrading enzyme. Appl. Environ. Microbiol. 64, 13661371

41 Nomura, N. et al. (2001) Gene structures and catalytic mechanisms of microbial enzymes able to biodegrade the synthetic solid polymers nylon and polyester polyurethane. Biotechnol. Gen. Eng. Rev. 18, $125-147$

42 Takwa, M. et al. (2006) One-pot difunctionalization of poly(omegapentadecalactone) with thiol-thiol or thiol-acrylate groups, catalyzed by Candida antarctica lipase B. Macromol. Rap. Comm. 27, 19321936

43 Mei, Y. et al. (2005) Biocompatibility of sorbitol-containing polyesters: Synthesis, surface analysis, and cell response in vitro. Polym. Biocatal. Biomat. 900, 343-353

44 Gustavsson, M.T. et al. (2004) Polyester coating of cellulose fiber surfaces catalyzed by a cellulose-binding module-Candida antarctica lipase B fusion protein. Biomacromol. 5, 106-112

45 Hilker, I. et al. (2006) Chiral polyesters by dynamic kinetic resolution polymerization. Angew. Chem. Int. Ed. 45, 2130-2132

46 Duxbury, C.J. et al. (2007) Selective Enzymatic Grafting by Steric Control. Macromol. Rap. Comm. 28, 235-240

47 Duxbury, C.J. et al. (2007) Enzyme responsive materials: chirality to program polymer reactivity. Angew. Chem. Int. Ed. 46, 84528454

48 Mueller, R.J. (2006) Biological degradation of synthetic polyestersEnzymes as potential catalysts for polyester recycling. Proc. Biochem. 41, 2124-2128

49 Yoon, M.Y. et al. (2002) Enzymatic modification of polyester. AATCC Review 2, 33-36

50 Nimchua, T. et al. (2007) Comparison of the hydrolysis of polyethylene terephthalate fibers by a hydrolase from Fusarium oxysporum LCH I and Fusarium solani f. sp. pisi. Biotechnol. J. $2,361-364$

51 Silva, C. et al. (2005) Cutinase-A New Tool for Biomodification of Synthetic Fibers. J. Polym. Sci. [B] 43, 2448-2450

52 Liebminger, S. et al. (2007) Hydrolysis of PET and bis(benzoyloxyethyl) terephthalate with a new polyesterase from Penicillium citrinum. Biocat. Biotrans. 25, 171-177

53 Hult, K. and Berglund, P. (2007) Enzyme promiscuity: mechanism and applications. Trends Biotechnol. 25, 231-238

54 Bornscheuer, U.T. and Kazlauskas, R.J. (2004) Catalytic promiscuity in biocatalysis: Using old enzymes to form new bonds and follow new pathways. Angew. Chem. Int. Ed. 43, 6032-6040

55 Secundo, F. et al. (2006) The lid is a structural and functional determinant of lipase activity and selectivity. J. Mol. Catal. B-Enz. 39, 166-170

56 Eggert, T. et al. (2004) Novel biocatalysts by identification and design. Biocat. Biotrans. 22, 139-144

57 Alisch-Mark, M. et al. (2006) Increase of the hydrophilicity of polyethylene terephthalate fibres by hydrolases from Thermomonospora fusca and Fusarium solani f. sp.pisi. Biotechnol. Lett. 28, 681-685

58 Alisch, M. et al. (2004) Biocatalytic modification of polyethylene terephthalate fibres by esterases from Actinomycete Isolates. Biocat. Biotrans. 22, 347-351

59 Fischer-Colbrie, G. et al. (2004) New enzymes with potential for PET surface modification. Biocat. Biotrans. 22, 341-346

60 Muller, R-J. et al. (2005) Enzymatic degradation of poly(ethylene terephthalate): Rapid hydrolyse using a hydrolase from $\mathrm{T}$. fusca. Macromol. Rap. Comm. 26, 1400-1405

61 Hooker, J. et al. (2002) Enzyme-Catalyzed Hydrolysis of Poly(ethylene terephthalate) Cyclic Trimer. J. Appl. Polym. Sci. 89, 2545-2552

62 Carvalho, C.M.L. et al. (1999) Cutinase: from molecular level to bioprocess development. Biotechnol. Bioeng. 66, 17-34

63 Creveld, L.D. et al. (2001) DSC studies of Fusarium solani pisi cutinase: consequences for stability in the presence of surfactants. Biophys. Chem. 92, 65-75

64 Longhi, S. and Cambillau, C. (1999) Structure-activity of cutinase, a small lipolytic enzyme. Biochim. Biophys. Act. 1441, 185-196 
65 Egmond, M.R. and de Vlieg, J. (2000) Fusarium solani pisi cutinase Biochimie 82, 1015-1021

66 Hiraishi, T. et al. (2006) Effects of mutations in the substrate-binding domain of poly[(R)-3-hydroxybutyrate] (PHB) depolymerase from Ralstonia pickettii $\mathrm{T} 1$ on $\mathrm{PHB}$ degradation. Appl. Environ. Microbiol. 72, 7331-7338
67 Takahashi, T. et al. (2005) The fungal hydrophobin RolA recruits polyesterase and laterally moves on hydrophobic surfaces. Molecul. Microbiol. 57, 1780-1796

68 Ohtaki, S. et al. (2006) Novel hydrophobic surface binding protein, HsbA, produced by Aspergillus oryzae. Appl. Environ. Microbiol. 72, $2407-2413$

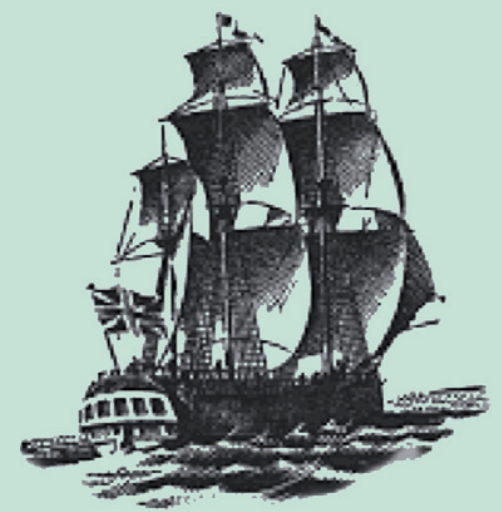

\section{Endeavour}

The quarterly magazine for the history and philosophy of science.

You can access Endeavour online on ScienceDirect, where you'll find book reviews, editorial comment and a collection of beautifully

illustrated articles on the history of science.

Featuring:

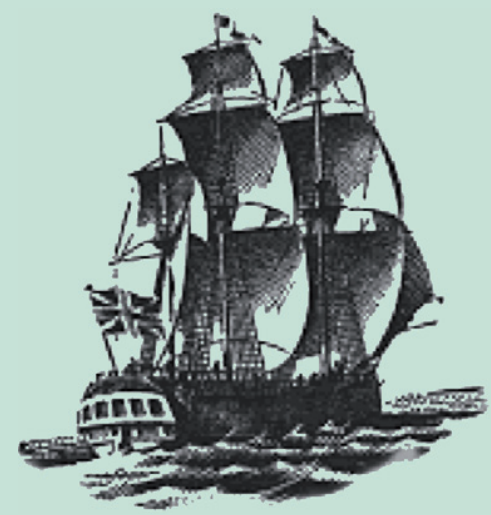

Information revolution: William Chambers, the publishing pioneer by A. Fyfe

Does history count? by K. Anderson

Waking up to shell shock: psychiatry in the US military during World War II by H. Pols

Deserts on the sea floor: Edward Forbes and his azoic hypothesis for a lifeless deep ocean by T.R. Anderson and T. Rice 'Higher, always higher': technology, the military and aviation medicine during the age of the two world wars by $\mathrm{C}$. Kehrt

Bully for Apatosaurus by P. Brinkman

\section{Coming soon:}

Environmentalism out of the Industrial Revolution by C. Macleod

Pandemic in print: the spread of influenza in the Fin de Siècle by J. Mussell

Earthquake theories in the early modern period by F. Willmoth

Science in fiction - attempts to make a science out of literary criticism by J. Adams

The birth of botanical Drosophila by S. Leonelli

And much, much more...

Endeavour is available on ScienceDirect, www.sciencedirect.com 